\title{
ALTAS HABILIDADES/SUPERDOTAÇÃO E DEFICIÊNCIA VISUAL: DUPLICIDADE DE NECESSIDADES EDUCACIONAIS ESPECIAIS
}

\author{
ALTAS HABILIDADES/SUPERDOTACIÓN Y DEFICIENCIA VISUAL: \\ DUPLICIDAD DE NECESIDADES EDUCACIONALES ESPECIALES
}

\author{
HIGH SKILLS/GIFTEDNESS AND VISUAL IMPAIRMENT: TWICE SPECIAL \\ EDUCATIONAL NEED
}

\author{
Rosemeire de Araújo RANGNI ${ }^{1}$ \\ Ailton Barcelos da COSTA ${ }^{2}$
}

RESUMO: A Educação Especial no Brasil é evidenciada, historicamente, à atenção aos indivíduos com deficiência. Os estudantes com alto potencial estão nas escolas, porém, com pouca visibilidade e reconhecimento. Infere-se que os estudantes em condição de altas habilidades/superdotação e deficiência são menos contemplados pelos serviços especiais. Este artigo objetiva revisar publicações sobre a duplicidade de necessidades educacionais especiais (DNEE), talento e deficiência visual, no período de 2002 a 2012, como também, considerar conceitos sobre talento e deficiência visual e refletir sobre a DNEE. Os métodos Bibliográfico e Documental foram usados para a realização da pesquisa. Procedeu-se buscas em livros especializados, documentos educacionais brasileiros e artigos publicados em revistas acadêmicas. Os resultados obtidos foram: em oito artigos encontrados somente três foram considerados relevantes para o propósito pesquisado. A maioria dos artigos nos sítios buscados não estava disponível de forma completa, apresentando apenas os resumos. Revelou-se, também, que há escassez de pesquisas sobre a temática no Brasil, especificamente sobre altas habilidades/superdotação e deficiência visual, pois, não foi encontrado nenhum trabalho no Portal de Periódicos da CAPES (Coordenação de Aperfeiçoamento de Pessoal de Nível Superior). Espera-se com este artigo contribuir para que os estudantes com DNEE sejam reconhecidos, de fato, por seus potenciais elevados.

PALAVRAS-CHAVE: Educação Especial. Superdotação. Cegueira.

ABSTRACT: Special Education in Brazil has historically been shown to care for individuals with disabilities. The students with high potential are in the schools, but with little visibility and recognition. It's concluded because the students in conditions of high abilities/giftedness and disability are less contemplated by special services. This paper aims to revise publications about the twice special educational needs (TSEN), talent and visual impairment, in 2002 to 2012, as well as to consider concepts about

\footnotetext{
${ }^{1}$ Doutora em Educação Especial - Universidade Federal de São Carlos - UFSCar. Pesquisadora na área de altas habilidades/superdotação, Políticas Públicas Educacionais e Educação Inclusiva. Professora Adjunta 1 na Universidade Federal de São Carlos - UFSCar. Email: rose.rangni@uol.com.br

2 Doutorando em Educação Especial na Universidade Federal de São Carlos. Email: ailton_barcelos@yahoo.com.br
} 
talent and visual impairment and also to reflect about TSEN. The Bibliographical and Documental methods were used. For this, it was proceeded searches in specialized books, Brazilian educational documents, and papers published in periodic. The results were: in eight papers searched only three ones were considered relevant for the research purpose. The majority of the papers available in the sites weren't in the complete form presenting only the abstract. It was revealed that there is scarce research about the thematic in Brazil, specifically, about high abilities/giftedness and visual impairment because it wasn't found any works in the Portal de Periódicos da CAPES (Coordenação de Aperfeiçoamento de Pessoal de Nivel Superior). It is waited with this paper to contribute for the students with TSEN are recognized, in fact, by their high potential.

KEYWORDS: Special Education. Giftedness. Blindness.

RESUMEN: La Educación Especial en Brasil se ha puesto de relieve, históricamente, en atención a los individuos con deficiencia. Los estudiantes con alto potencial están en las escuelas, pero, con poca visibilidad y reconocimiento. Se infiere que los estudiantes en condición de altas habilidades/superdotación y deficiencia son menos considerados por los servicios especiales. Este artículo tiene el objetivo de revisar publicaciones sobre la duplicidad de necesidades educacionales especiales (DNEE), talento y deficiencia visual, en el periodo de 2002 a 2012, como también, considerar conceptos sobre talento y deficiencia visual y reflexionar sobre la DNEE. Los métodos Bibliográfico y Documental fueron usados para la realización de la investigación. Se procedieron buscas en libros especializados, documentos educacionales brasileños y artículos publicados en revistas académicas. Los resultados obtenidos fueron: de los ocho artículos encontrados solamente tres fueron considerados relevantes para el propósito investigado. La mayoría de los artículos en los sitios buscados no estaba disponible de forma completa, presentando solo los resúmenes. Se observó también que hay escasez de investigaciones sobre la temática en Brasil, específicamente sobre altas habilidades/superdotación y deficiencia visual, pues, no fue encontrado ningún trabajo en el "Portal de Periódicos de la CAPES" (Coordinación de Perfeccionamiento de Personal de Nivel Superior). Se espera con este artículo contribuir para que los estudiantes con DNEE sean reconocidos, de hecho, por sus potenciales elevados.

PALABRAS CLAVE: Educación Especial. Superdotación. Ceguera.

\section{Introdução}

As pessoas com capacidade superior têm sido alvos de interesse desde a antiguidade, encontrando-se registros sobre esse interesse na Grécia, Roma, China e Egito. Apesar dos povos antigos valorizarem os indivíduos que se destacavam, ainda ocorre nos dias de hoje resistências por parte da escola em reconhecê-los.

Ao abordar a inclusão de estudantes com necessidades educacionais especiais, normalmente, os olhares se voltam àqueles com deficiência ou síndrome. Este tem sido um cenário comum no contexto da Educação Especial, mesmo tentando-se atenuar esses 
efeitos com os movimentos após a Declaração de Salamanca em 1994, e os dispositivos legais dela decorrentes, quais sejam: Lei de Diretrizes e Bases da Educação Nacional (BRASIL, 1996), Diretrizes Nacionais para a Educação Especial na Educação Básica (BRASIL, 2001) e Política Nacional de Educação Especial na Perspectiva da Educação Inclusiva (BRASIL, 2008), entre outros.

Apesar de o Brasil participar como signatário de Salamanca, ainda averígua-se lentidão nas iniciativas e ações em reconhecer os estudantes com altas habilidades/superdotação nas escolas do país. De acordo com informação oferecida pela Fiocruz (BRASIL, 2012), há cerca de 13.000 alunos matriculados na rede de ensino brasileira.

Esse advento de letargia se fortalece quando, particularmente, trata-se de possibilidades dos estudantes com deficiência possuir capacidade elevada. É o caso da duplicidade de necessidades educacionais especiais (DNEE) - altas habilidades/superdotação e deficiência, ou seja, deficiência visual, condição abordada neste artigo.

Percebe-se, que no cenário educacional brasileiro as matrículas de estudantes que se destacam de seus pares são aquém se comparadas às matrículas de alunos com alguma deficiência. Nesta ótica, o atendimento se faz escasso, tanto para os estudantes que possuem apenas altas habilidades/superdotação, como também, praticamente inexistente para os que possuem DNEE.

Assim sendo, devido à escassez de estudos e publicações sobre essa temática que pudessem subsidiar as reflexões e discussões, decidiu-se pelo desenvolvimento deste artigo.

\section{Objetivo}

Verificar na literatura científica brasileira e internacional publicada no período de 2003 a 2013, o conteúdo dos estudos empíricos que tratam da interação duplicidade de necessidades educacionais especiais, talento e deficiência visual, trazendo reflexões sobre a duplicidade de necessidades educacionais especiais - DNEE.

\section{Método}

Foram realizadas buscas sistemáticas baseadas em trabalhos empíricos qualitativos, nacionais e internacionais, publicados entre os anos de 2003 e 2013. 
Buscas essas indexadas na base de dados da Biblioteca Virtual SciELO Brasil Scientific Electronic Library Online, no Portal de Periódicos da CAPES (Coordenação de Aperfeiçoamento de Pessoal de Nível Superior), na base de dados ERIC (Education Resources Information Center), e no Catálogo de Publicaciones de Servicios Sociales. Também, para embasamento teórico, foram utilizadas buscas em livros especializados e documentos oficiais brasileiros.

Efetuaram-se tais buscas a partir de descritores e/ou palavras chave representativos à temática de investigação, que foram utilizados isoladamente e em associação: 'visual impairment', 'blindness', 'giftedness', 'talent', 'high ability', tais termos também buscados em espanhol e português.

Para análise dos dados, produziram-se categorias sobre características e conteúdos presentes nos artigos (fichamentos), baseados em Silveira, Enuno e Rosa (2012).

\section{Altas habilidades/superdotação}

No Brasil, os registros apontam iniciativas a essa população em pesquisas com Ulisses Pernambucano, em 1929, e com a publicação por Leoni Kaseff da obra “Educação dos Supernormaes”, em 1931 (GAMA, 2006).

Em 1945, Helena Antipoff, cientista russa, iniciou trabalhos que visavam o atendimento aos mais capazes no Instituto Pestalozzi, no Rio de Janeiro. Desde essa data, Antipoff prosseguiu seu intento e fundou na Fazenda do Rosário, em Ibirité/MG, em 1962, a primeira tentativa de reunir um grupo de adolescentes talentosos do meio rural (NOVAES, 1979, p. 80). Engajada na luta em prol do trabalho educacional a esses indivíduos, Antipoff fez parte da equipe de especialistas que conseguiu realizar em 1971 o Primeiro Seminário para Superdotados no Brasil e logrou êxito na inclusão dos estudantes com potencial elevado na Lei de Diretrizes e Bases da Educação, ${ }^{\circ}$ 5.692, artigo $9^{\circ}$ (BRASIL, 1971). Desde então, as altas habilidades/superdotação têm sido mantidas nos documentos pertinentes à Educação Especial, quais sejam: Lei de Diretrizes e Bases da Educação Nacional - LDBEN 9.394 (BRASIL, 1996); Resolução n 02 (BRASIL, 2001); Políticas Nacionais de Educação Especial na Perspectiva de Educação Inclusiva (BRASIL, 2008), como necessidade educacional especial ${ }^{3}$.

${ }^{3}$ Superdotados foi o termo utilizado na Lei de Diretrizes e Bases 5.692, de 1971, artigo $9^{\circ}$. Superdotados foi mencionado na Lei de Diretrizes e Bases da Educação Nacional 9.394, de 1996 e alterada na Lei 
A Resolução no 02 (BRASIL, 2001) que, instituiu as Diretrizes Nacionais para Educação Especial na Educação Básica, em seu artigo 5, III traz a seguinte definição: "altas habilidades/superdotação, grande facilidade de aprendizagem que os levem a dominar rapidamente os conceitos, os procedimentos e as atitudes".

A Política Nacional para a Educação Especial na Perspectiva da Educação Inclusiva (BRASIL, 2008) aponta três grupos considerados públicos contemplados para o atendimento da Educação Especial, quais sejam: a deficiência, transtornos globais do desenvolvimento e altas habilidades/superdotação, e define este grupo como:

\begin{abstract}
Alunos com altas habilidades/superdotação demonstram potencial elevado em qualquer uma das seguintes áreas, isoladas ou combinadas: intelectual, acadêmica, liderança, psicomotricidade e artes. Também apresentam elevada criatividade, grande envolvimento na aprendizagem e realização de tarefas em áreas de seu interesse (BRASIL, 2008, p. 9).
\end{abstract}

É importante ressaltar que a terminologia foi alterada de altas habilidades (superdotados) para altas habilidades/superdotação e o quesito psicomotor para psicomotricidade em relação à Política anterior, de 1994.

Em termos legais, pode-se dizer que os educandos com altas habilidades/superdotação estão bem amparados. No entanto, não ocorre o mesmo quanto à sua identificação e serviços de atendimento especializado.

Visualiza-se, por meio da literatura especializada da área, que os mitos ou falsos conceitos rodeiam o universo das pessoas que se destacam de seus pares e, possivelmente, se constituem em entraves para ações educacionais em favor do reconhecimento desses estudantes. Rech e Freitas (2010, p. 68) destacam alguns desses mitos:

Criança superdotada, um "adulto partido ao meio";

Criança superdotada, um "adulto partido ao meio";

Todo superdotado é um gênio;

Superdotado como um "sabe-tudo";

O superdotado é cem por cento: o mais arrumadinho, disciplinado e obediente;

Todo superdotado é bem-sucedido na escola;

Superdotação indicador de: rebeldia, desrespeito, desobediência, atrevimento, ousadia e "do contra";

Superdotação: condição suficiente para alta produtividade;

Toda criança com indício de superdotação "é superdotada";

12.796 (BRASIL, 2013) para Altas habilidades ou superdotação. Altas habilidades/superdotação constam na Resolução n 2 (BRASIL, 2001) e Política Nacional de Educação Especial na Perspectiva da Educação Inclusiva (BRASIL, 2008). 
Todo superdotado é "meio maluco";

Todo superdotado foi criança precoce, um "prodígio";

Superdotação não, superestimulado e

Superdotado só procede de família rica (RECH; FREITAS, 2010, p. $68)$.

Ao invés de mitos, Guenther (2011) prefere admitir que eles são falsos conceitos que contrariam os últimos avanços da ciência. Apenas exemplificando, em um dos mitos apontados - "todo superdotado é bem-sucedido na escola" - uma pessoa com indicadores de alta capacidade não tem que ser necessariamente bem sucedida na vida ou na escola. Alunos podem apresentar baixo rendimento escolar quando o processo de ensino não os favorecem. Esse aspecto obscurece a emersão de seus potenciais e os tornam invisíveis aos professores em reconhecê-los (GAGNÉ, 2008; PÉREZ e FREITAS, 2010).

Quanto aos indicadores das altas habilidades/superdotação, vários autores apresentam listas, dentre eles Galbraith e Delisle (1996) citados em BRASIL (2007, p.4), quais sejam:

Aprende fácil e rapidamente;

Original, imaginativo, criativo, não convencional;

Amplamente informado, informado em áreas não comuns;

Pensa de forma incomum para resolver problemas;

Persistente, independente, não direcionado (faz coisa sem que seja mandado);

Persuasivo, capaz de influenciar os outros;

Mostra senso comum, pode não tolerar tolices;

Inquisitivo, cético, curioso sobre o como e porque das coisas;

Adapta-se a uma variedade de situações e novos ambientes;

Esperto ao fazer coisas com materiais comuns;

Habilidades nas artes (música, dança, desenho, etc.);

Entende a importância da natureza (tempo, lua, sol, estrelas, solo, etc.);

Vocabulário excepcional, verbalmente fluente;

Aprende facilmente novas línguas;

Trabalhador independente, mostra iniciativa;

Bom julgamento, lógico;

Flexível, aberto;

Versátil, muitos interesses, interesses além da idade cronológica;

Mostra insights e percepções incomuns;

Demonstra alto nível de sensibilidade, empatia com relação aos outros;

Apresenta alto senso de humor;

Resiste à rotina e repetição;

Expressa ideias e reações, frequentemente de forma argumentativa e Sensível à verdade e à honra (BRASIL, 2007, p.4). 
Certamente, há uma variedade de características assinaladas por diversos autores. No entanto, vale frisar que apontar os estudantes por suas características, nas escolas, sem oferecer provisão educacional, torna-se inútil; servirá apenas para rotulá-las ainda mais.

\section{Deficiência Visual}

Destacando-se alguns conceitos em relação à deficiência visual (cegueira e baixa visão), pode-se começar por acuidade visual, entendida como a capacidade de discriminação de formas, e, que é medida por oftalmologistas por meio de apresentações de linhas, símbolos ou letras em tamanhos diversificados. A pessoa com baixa acuidade visual apresenta dificuldades para perceber formas, sejam de perto, longe, ou em ambas as situações; já o campo visual é avaliado a partir da fixação do olhar, quando é determinada a área circundante visível ao mesmo tempo (MUNSTER; ALMEIDA, 1984). Do ponto de vista médico, na Classificação Internacional de Doenças (CID - 10) (ORGANIZAÇÃO MUNDIAL DE SAÚDE, 2007), a definição de visão subnormal ou baixa visão considera que a acuidade visual corrigida no melhor olho é menor do que 0,3 e maior do que 0,05 , ou o campo visual é menor do que 20 graus no melhor olho com a melhor correção óptica, e a definição de cegueira dada quando esses valores encontram-se abaixo de 0,05 ou o campo visual menor do que 10 graus.

A partir disso, Leonhardt (1992) classifica potencial de visão de pessoas cegas em congênito e adquirido. A primeira, continua o autor, se aplica àquelas pessoas que apresentam cegueira no momento do nascimento, ou em um período imediato. Entretanto, as pessoas com cegueira adquirida, de acordo com o mencionado autor, são aquelas que ficaram cegas depois dos doze meses de vida, às quais devem ter enxergado com grande dificuldade, durante as primeiras etapas de vida, embora elas não tenham recebido informações visuais úteis, ou seja, receberam a formação de estruturas mentais baseadas na visão (LEONHARDT, 1992).

Em relação à definição do potencial de aprendizagem de cada pessoa, é importante tomar a perspectiva educacional. Barraga (1985) define as pessoas com baixa visão compreendendo aquelas que possuem resíduo visual que lhes permite ler textos impressos em tinta, desde que recorrendo a recursos didáticos e/ou equipamentos especiais. Assim, a pessoa cega é aquela cuja percepção de luz, embora possa auxiliá-la 
em seus movimentos e orientação, é insuficiente para aquisição de conhecimento por meios visuais, necessitando utilizar o sistema Braille em seu processo de ensinoaprendizagem.

Em complemento, Bruno (2001) comenta que o processo educacional acontecerá por meio da utilização não só do sistema Braille, mas de seus sentidos remanescentes, como a audição, o tato, o olfato o paladar.

Outra consideração importante sobre as possibilidades de aprendizagem das pessoas com deficiência visual diz respeito ao desenvolvimento do tato ou tátilcenestésico. Lewis (2003) assinala que essas são habilidades cognitivas de conhecimento e atenção exploratórias por meio das quais as crianças com deficiência visual conseguem diferenciar as qualidades dos objetos. Por isso, a importância de se manipular, conhecer seus tamanhos, pesos, texturas, consistências, temperaturas, e assim obter informações sobre as substâncias. Além disso, Lewis (2003) pontua que à medida que as crianças aprendem a discriminar os objetos, é preciso introduzir progressivamente a linguagem que ensina o reconhecimento dos objetos específicos pelo nome, ou seja, no processo de aprendizagem tátil. Também, explicita o referido autor, que a linguagem é igualmente importante, uma vez que conduz à maior abstração, a níveis mais elaborados da capacidade de discriminar e reconhecer símbolos, podendo, desta forma, reconhecer os sinais do sistema Braille que, pressupõe-se, um alto nível de abstração e associação cognitiva.

\section{Duplicidade de necessidades educacionais especiais (DNEE)}

Partindo-se do fato de que há alunos que apresentam mais de uma necessidade educacional especial (NEE), mais precisamente os que apresentam altas habilidades/superdotação e deficiência visual, faz-se pretenso discorrer algumas reflexões sobre essa questão.

A literatura especializada é escassa ao tratar da temática, principalmente a brasileira. Ourofino e Fleith $(2005$, p. 166) assinalam que, em relação à dupla condição de necessidade educacional especial, "nos últimos anos, nota-se um tímido aumento no número de estudos empíricos sobre o tema".

Também, Gerlach (2008, p. 12) explicita que: 
Muitos educandos com dupla excepcionalidade são deixados à margem em programas especiais por causa de sua força e capacidade para compensar suas dificuldades. Além do mais, o mito prevalente que educação para talentosos e educação especial estão em oposição e tendem a fazer a identificação da dupla excepcionalidade mais problemática. $^{4}$

É notória a necessidade de estudos que contemplem esse grupo de pessoas.

As poucas publicações sobre a temática, possivelmente, seja um dos entraves para que as bases teóricas e as práticas não cheguem às escolas para auxiliar no reconhecimento e serviços especializados às suas necessidades específicas (RANGNI, 2012).

Sobre essa escassa literatura, especificamente quanto ao talento em pessoas com deficiência visual, Starr (2003) considera a dificuldade de mensuração eficaz para detectar as capacidades superiores, no entanto, a mesma autora assinala que a literatura ressalta que as pessoas com deficiência visual tendem a ter resultados altos em fluência, flexibilidade e originalidade verbal em testes de escala verbal, como o Wechsler Intelligence Scale for Children - WISC.

Ainda sobre a flexibilidade verbal, um estudo apresentado em 1968, por William (1968), da School of Education, University of Briminghan, expõe que crianças e adolescentes com retinoblastoma (tumor maligno no olho originado de células imaturas) obtiveram scores mais altos em testes de Q.I que àqueles com outras causas de cegueira. O teste utilizado na ocasião da pesquisa foi o Williams Intelligence Test Scale, baseado no Simon - Binet Type e os itens são predominantemente verbais. Isso comprova que a potencialidade nessas pessoas já tem sido verificada há algum tempo, no entanto, pouco pesquisada.

Starr (2003), por meio das indicações de Johnson e Corn (1989), pontuam quatro impedimentos à identificação dos estudantes com DNEE, quais sejam: i) Conhecimento łlimitado de pais e profissionais quanto a DNEE; ii) Falta de atitude positiva dos professores em relação à identificação e inclusão em programas de atendimento; iii) Métodos inapropriados de identificação; e iv) Limitação de recursos para os programas de provisão educacional.

Em uma pesquisa realizada por Starr (2003), em cinco estudantes talentosos com deficiência visual, com idades entre 3 a 16 anos, na Austrália, com instrumentos como: WISC, Escala de Autoconceito para Crianças de Piers Harris, de 1984; Checklista de

4 Tradução dos autores. 
Identificação para Pais (Victorian Directorate of School Education); Inventário para Pais sobre Inteligências Múltiplas de Shannon (1991); Formulário para pais de Habilidades Sociais; Escala de Características de Renzulli-Hartman, de 1971 e Formulário para Professores de Gresham e Elliot, 1990, sinteticamente foram encontrados no estudo ao resultados:

- Todos os estudantes pesquisados apresentaram altos scores em subtestes de compreensão e demonstraram alto desenvolvimento sobre regras e convenções sociais por meio de explicações. Também os participantes obtiveram elevados resultados em subteste de similaridades e as informações verbais resultaram em um alto grau de abstração.

- Quatro estudantes apresentaram bons níveis de autoestima, exceto um estudante, pois seu autoconceito foi baixo comparado aos outros estudantes. Isso pode ser explicado pelo fato da transição do aluno para o nível secundário.

- As habilidades sociais indicaram que quatro estudantes obtiveram níveis acima da média em assertividade, cooperação, responsabilidade e autocontrole. Somente um estudante acusou, pelo professor, baixo autocontrole e cooperação.

As múltiplas inteligências, baseadas na ocasião do estudo em sete Inteligências Múltiplas, mostraram preferências por música, pois todos tocam instrumentos. Os pais também assinalaram preferências de seus filhos nas Inteligências Linguística e Matemática. Um estudante resultou em dificuldade espacial, possivelmente devido à idade (Starr, 2003).

O estudo concluiu que todos os participantes foram indicados com alto nível de atenção e concentração e há necessidade de adaptar os instrumentos para esses estudantes e aperfeiçoar oportunidades para receberem serviços adequados.

\section{Resultados e discussão}

Em buscas realizadas com intuito de encontrar publicações referentes à DNEE altas habilidades/superdotação e deficiência visual - no período compreendido de 2003 a 2013, foram encontrados os seguintes resultados:

Descritores e/ou palavras chave buscadas isoladas ou combinadas: 'visual impairment', 'giftedness', 'visual impairment', 'high ability', 'blindness', 'giftedness', 'talent', e seus referentes na língua portuguesa e espanhola.

Nas bases de dados, quais sejam: Biblioteca Virtual SciELO Brasil - Scientific Electronic Library Online, Portal de Periódicos da CAPES (Coordenação de 
Aperfeiçoamento de Pessoal de Nível Superior), Education Resources Information Center - ERIC, não foram encontrados resultados que contemplasse altas habilidades/superdotação e deficiência visual.

No Catálogo de Publicaciones de Servicios Sociales, com os descritores assinalados, foi possível encontrar oito resultados. No entanto, para efeito de adequação ao período de 2003 a 2013, desta pesquisa, apenas três artigos foram considerados relevantes, em relação à periodicidade da publicação e abrangência da temática, quais sejam:

O primeiro trabalho a ser analisado foi o de Besnoy, Manning e Karnes (2005), que expõe a falta de atendimento educacional de estudantes com deficiência visual, e para tanto, pontua uma estimativa da Fundação Americana para Deficiência Visual que aponta que em 2004 havia 94.000 estudantes com deficiência visual nas escolas públicas americanas, e que $5 \%$ dessa população era considerada com altas habilidades/superdotação. O propósito do trabalho foi aumentar a compreensão sobre as altas habilidades/superdotação no grupo de indivíduos com limitações visuais e inserilos em programas de atendimento, e, assim, aliviar a sub-representação em tais programas.

O segundo, de Memmert (2006), trata-se de um estudo longitudinal, de seis meses, em 33 crianças com altas habilidades/superdotadas de um programa de enriquecimento esportivo, que resultou o desenvolvimento do pensamento criativo nos participantes da pesquisa, em contraste ao grupo controle de crianças sem indicadores de altas habilidades/superdotação. Baseado nesses dados, o mencionado autor apresenta um segundo experimento sobre diferenças individuais de atenção em dois grupos de indivíduos: 54 crianças com altas habilidades/superdotação e 58 sem altas habilidades/superdotação. Segundo os resultados, as amostras pontuam diferenças significantes em condições próximas, mas não apresentam em condições distantes. Essas conexões foram discutidas e pautadas em pesquisas mais antigas.

Por fim, o trabalho de Matawa (2009), explora os interesses e talentos de crianças e jovens cegos, ou com baixa visão, consequência da retinopatia de prematuridade (RoP). No total, 37 pais responderam que a música é uma parte significante da vida de seus filhos com RoP e podem apresentar capacidade musical.

Averigua-se que dos oito trabalhos encontrados, foram considerados relevantes apenas três, mas nenhum deles é voltado para a DNEE, revelando a escassez de 
pesquisas e discussões sobre a temática da DNEE referente aos indivíduos com altas habilidades/superdotação e deficiência visual.

Dessa maneira, depois de discorrer sobre os três trabalhos encontrados, pode-se inferir que houve tentativa em oferecer compreensão sobre o reconhecimento das altas habilidades/superdotação em pessoas com deficiência visual e a possibilidade em inserilos em programas para desenvolver os talentos. Importante assinalar que os estudos são baseados em pesquisas não tão recentes, o que denota a necessidade de se buscar novas investigações sobre a temática.

\section{Conclusão}

No cenário brasileiro, por um lado, percebe-se que, no movimento da educação inclusiva, maiores iniciativas são desencadeadas em prol dos estudantes com deficiências. Iniciativas essas amparadas por laudos clínicos, materiais, recursos e procedimentos de ensino para que sejam recebidos nos sistemas escolares de forma a garantir respostas educativas às suas necessidades.

Por outro lado, os estudantes com indicadores de altas habilidades/superdotação já se encontram nas escolas, mas sem reconhecimento de seus potenciais, pelo menos oficialmente. Esse fato é constado pelas ínfimas matrículas, cerca de 13.000, em todo o país.

No que concerne à DNEE, altas habilidades/superdotação e deficiência visual, suspeita-se que há muitos estudantes não reconhecidos, possivelmente, por conta da visualização da incapacidade e não das potencialidades nos indivíduos com deficiência. Além do mais, as barreiras burocrático/administrativas que se expressam em exigências de laudos que comprovem as altas habilidades/superdotação criam barreiras para que os sistemas escolares recebam o repasse de recursos, já que a dupla matrícula é contemplada, regida em dispositivos legais referentes ao atendimento educacional especializado. Além do mais, em caso de DNEE, como seria o atendimento ou mesmo o repasse de recursos?

Desta forma, espera-se com este artigo, contribuir para o prosseguimento das reflexões e discussões sobre a condição da DNEE nos estudantes do sistema de ensino brasileiro que aguardam serem vistos, também, por suas potencialidades. Que os estudos e pesquisas sobre a temática tenham aumento significativo para auxiliar a 
minimizar o preconceito sobre as pessoas com deficiências e definitivamente sejam reconhecidas por suas potencialidades.

\section{REFERÊNCIAS}

BARRAGA, N. C. Disminuidos visuales y aprendizaje. Madrid: ONCE, 1985.

BRASIL. Lei de Diretrizes e Bases. Ministério da Educação, Brasília, 1971.

Lei de Diretrizes e Bases da Educação Nacional. Lei n. 9.394, de 20 de dezembro de 1996. Disponível em: 〈www.planalto.gov.br/legislação>. Acesso em 07/04/2010.<http://portal.mec.gov.br/seesp/arquivos/pdf/altashab1.pdf> .Acesso em 10 fev. 2012.

. Resolução no 02, de 11 de setembro de 2001. Institui Diretrizes Nacionais para a Educação Especial na Educação Básica. Disponível em:

<http://portal.mec.gov.br/cne/arquivos/pdf/CEB0201.pdf > Acesso em 04 abr. 2011.

Altas habilidades/superdotação: encorajando potenciais. Ministério da Educação/Secretaria de Educação Especial: Brasília, DF, 2007. Disponível em: http://portal.mec.gov.br/seesp/arquivos/pdf/altashab1.pdf. Acesso em: 18 fev. 2014.

\section{. Política Nacional de Educação Especial na Perspectiva da Educação}

Inclusiva. Ministério da Educação / Secretaria de Educação Especial, Brasília, DF, 2008. Disponível em:<http://www.mec.gov.br/seesp>. Acesso em 07 abr. 2012.

. FIO CRUZ. Altas habilidades. Rio de Janeiro: Canal Saúde/Fio Cruz, 13/06/2012 [online]. Entrevista. Disponível em:

<http://www.canal.fiocruz.br/video/index.php?v=altas-habilidades>. Acesso em: 14 jun. 2012.

. Lei 12.796/13, de 4 de abril de 2013. Altera a Lei no 9.394, de 20 de dezembro de 1996, que estabelece as diretrizes e bases da educação nacional, para dispor sobre a formação dos profissionais da educação e dar outras providências. 2013. Disponível em: <http://www.planalto.gov.br/ccivil_03/_ato2011-2014/2013/lei/112796.htm>. Acesso em 10 abr. 2014.

BRUNO, M. M. G. Compreendendo a baixa visão. In: Bruno, M. M. G.; Mota, M. D. G. B. (Orgs.). Programa de capacitação de recursos humanos do ensino fundamental: deficiência visual. Brasília: Ministério da Educação, 2001.

GAGNÉ, F. Building gifts into talents. Talent development according to the DMGT. Veröffentlicht in: news\&science. Begabtenförderung und Begabungsforschung. özbf, Nr. 19/Ausgabe 2, 2008, S. 27-30. 
GAMA, M. C. S. S. Educação de superdotados: teoria e prática. São Paulo: EPU, 2006.

GERLACH, J. Brilliant chaos: understand twice exceptional students. TEMPO, vol. XXVIII, Issue 4, Texas Association for the gifted and Talented, 2008.

GUENTHER, Z. C. Crianças dotadas e talentosas... Não as deixem esperar mais. Rio de Janeiro: LTC, 2011.

LEONHARDT, M. El bebé ciego: primera atención - Un enfoque psicopedagógico. $1^{\text {a }}$ Ed. Barcelona/España: ONCE, 1992.

LEWIS, V. Development and Disability. 2. ed., Oxford: Blackwell Publishing, 2003.

MUNSTER, M. A. V.; ALMEIDA, J. J. G. Atividade física e deficiência visual. In: PESSOTTI, I. Deficiência mental: da superstição à ciência. São Paulo: Editora da Universidade de São Paulo, 1984.

NOVAES, M. H. Desenvolvimento psicológico do superdotado. São Paulo: Atlas, 1979.

ORGANIZAÇÃO MUNDIAL DA SAÚDE. Classificação estatística internacional de doenças e problemas relacionados à saúde: CID-10. São Paulo: EDUSP, 2007.

OUROFINO, V. T. A. T. Altas habilidades e hiperatividade: a dupla excepcionalidade. In: FLEITH, D.S.; ALENCAR, E. M. L. S. (Orgs.) Desenvolvimento de talentos e altas habilidades. Orientação para pais e professores. Porto Alegre: Artmed, 2005.

PÉREZ, S. G. P. B.; FREITAS, N. S. Altas habilidades/superdotação. Atendimento especializado. Marília: abpee, 2006.

RANGNI, R. A. Reconhecimento do talento em alunos com perdas auditivas no ensino básico. (Tese de Doutorado). Programa de Pós-Graduação em Educação Especial, Universidade Federal de São Carlos, 2012.

RECH, J. D.; FREITAS, S. N. Uma revisão bibliográfica sobre os mitos que envolvem as pessoas com altas habilidades In: FREITAS, S. N. (Org.) Educação e altas habilidades/superdotação: a ousadia de rever conceitos e práticas. Santa Maria: Editora UFSM, 2006.

SILVEIRA, K. A; ENUMO, S. R. F.; ROSA, E. M. Concepções de professores sobre inclusão escolar e interações em ambiente inclusivo: uma revisão da literatura. Rev. bras. educ. espec., Marília, v. 18, n. 4, Dec. 2012.

STARR, R. Show me de light - I can't see how bright I am: gifted students with visual impairment. In: MONTGOMERY, D. Gifted \& Talented Children with Special Educational Needs: Double Montgomery. London: A NACE/Fulton Publication, 2003.

WILLIAM, M. Superior intelligence of children blinded from retinoblastoma. School of Education, University of Birminghan, Arch. Dir. Childh, 1968. 


\section{Como referenciar este artigo}

RANGNI, Rosemeire de Araújo.; COSTA, Ailton Barcelos da. Altas habilidades/superdotação e deficiência visual: duplicidade de necessidades educacionais especiais. Revista Ibero-Americana de Estudos em Educação, Araraquara, v. 11, n. 4, p. 1979-1993, 2016. Disponível em: 〈http://dx.doi.org/10.21723/riaee.v11.n4.7387〉. E-ISSN: 1982-5587.

Submissão em: novembro/2014

Aprovação final em: novembro/2016 